\title{
Fluid Flow Phenomena in a Cylindrical Bath Agitated by Top Lance Gas Injection
}

\author{
Manabu IGUCHI, Tomomasa UEMURA, ") Hiroshi YAMAGUCHI, ${ }^{2)}$ Tomoaki KURANAGA ${ }^{3)}$ and \\ Zen-ichiro MORITA4)
}

Faculty of Engineering, Osaka University, Yamadaoka, Suita, Osaka-fu, 565 Japan.

1) Faculty of Engineering, Kansai University, Yamatecho, Suita, Osaka-fu, 564 Japan.

2) Undergraduate Student, Faculty of Engineering, Osaka University. Now Kubota Corporation. Oh-ike, Nakamiya, Hirakata, Osaka-fu, 573 Japan.

3) Undergraduate Student, Faculty of Engineering, Osaka University. Now Graduate Student, The University of Tokyo, Roppongi, Minato-ku, Tokyo, 106 Japan. 660 Japan.

4) Professor Emeritus, Osaka University. Now Sumitomo Metal Industries Ltd., Fuso-cho, Amagasaki, Hyogo-ken,

(Received on June 2, 1994; accepted in final form on September 16, 1994)

Fluid flow phenomena in a cylindrical bath agitated by gas injection from a submerged top lance were investigated on the basis of cold model experiments. A swirl motion of liquid, which was similar to the rotary sloshing, was observed under a certain blowing condition. The critical condition for the cessation of the swirl motion was first experimentally clarified and subsequently the following experiments were made in the absence of the swirl motion.

The vertical migration distance of bubbles from the lance exit was measured using an electro-resistivity probe, and an empirical correlation for it was proposed as a function of the modified Froude number. The axial and radial velocity components of liquid were measured for a water-air system using a two-dimensional laser Doppler velocimeter. Applicability of previous empirical correlations of the axial mean velocity proposed for the gas injection through a centric bottom nozzle to the present case was examined. An electro-chemical method was used to measure the mass transfer coefficient between a platinum flat plate and aqueous $\mathrm{FeSO}_{4}$ solution. In the region below the bubble plume, the so-called dead water region was observed.

KEY WORDS: injection metallurgy; top lance; swirl motion; velocity measurement; laser Doppler velocimeter; mass transfer; gas holdup.

\section{Introduction}

Fundamental studies on the mass transfer between liquid and gas and mixing time in a bath agitated by gas injection through a submerged top lance have been extensively made for the improvement of conventional steelmaking processes. $^{1-3)}$ However, knowledge on liquid flows induced in the bath by top lance blowing is limited.

When gas was injected vertically downward into a bath through a submerged top lance, a swirl motion similar to that observed in a bath agitated by bottom gas injection appeared. ${ }^{4,5)}$ If such a swirl motion occurs in practical metallurgical reactors, molten metal in the reactors would oscillate violently and hence erosion of the wall material would become serious.

In this study a critical condition describing the occurrence of the swirl motion was investigated for water and mercury baths by changing the nozzle diameter, gas flow rate, and immersion depth of the lance. Next, the downward migration distance of bubbles injected through the submerged top lance into the bath was measured in the absence of the swirl motion using a two-needle electro-resistivity probe for water-air, aqueous glycerol solution-air, mercury-air, and Wood's metal- $\mathrm{N}_{2}$ systems. An empirical correlation of the downward migration distance was derived by referring to experimental results for horizontal gas injections.

The axial and radial velocity components of liquid motion induced by bubbling jet were measured using a laser Doppler velocimeter (LDV) for a water-air system. In addition, the mass transfer coefficient between a solid body and liquid was measured by the electro-chemical method.6) Experimental results of liquid velocity and mass transfer revealed the existence of the so-called dead water region in the lower part of the bath.

\section{Experiment}

\subsection{Swirl Motion}

When gas was injected into a bath through a top lance submerged coaxially with the bath, a swirl motion occurred at a certain gas flow rate as schematically shown in Fig. 1. It should be noted that a nozzle is attached to the exit of the lance. The swirl motion ceased when the submerged depth of the nozzle, i.e., the distance from the bath surface to the nozzle exit exceeded a critical value. This distance was defined as the critical depth $L_{n}$ 


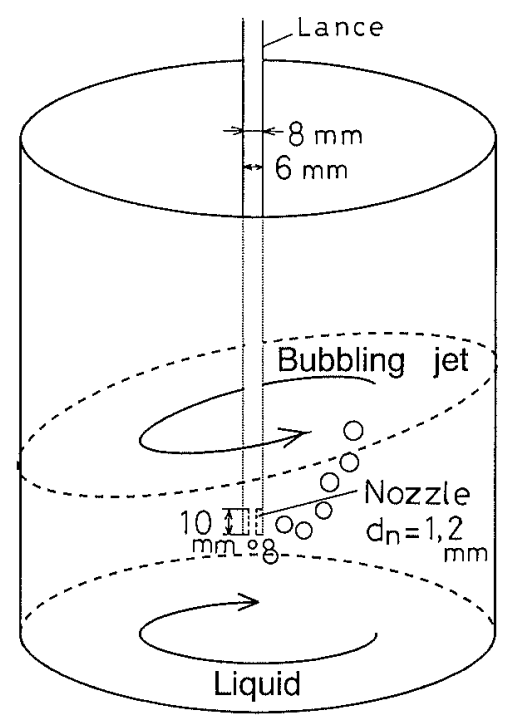

Fig. 1. Schematic illustration of swirl motion caused by gas injection through a submerged top lance.

for the cessation of the swirl motion.

Water and mercury were used as the models of molten steel, and air was used as the injection gas. Acrylic vessels having inner diameters of 123,200 , and $390 \mathrm{~mm}$ were used for the water-air system. Cylindrical vessels made of brass having inner diameters of 125 and $155 \mathrm{~mm}$ were employed for the mercury-air system. Fluoro-resin was coated on the side and bottom walls of the brass vessels to prevent reaction between mercury and brass. The outer diameter of a lance made of brass was 8 or $20 \mathrm{~mm}$. The inner diameter of a nozzle made of brass or acrylic resin was 1 or $2 \mathrm{~mm}$. The maximum volumetric gas flow rate at the nozzle exit was $300 \mathrm{~cm}^{3} / \mathrm{s}$.

The following subjects were investigated in the absence of the swirl motion.

\subsection{Downward Migration Distance of Bubbling Jet Measured with an Electro-resistivity Probe}

\subsubsection{Definition of the Downward Migration Distance of Bubbling Jet}

The downward migration distance of bubbling jet injected through a submerged top lance into water, aqueous glycerol solution, mercury or Wood's metal bath was measured with an electro-resistivity probe (see Fig. 2).

Gas holdup $\alpha$ was measured using the electro-resistivity probe. Its output signal was $A / D$ converted at a sampling frequency of $5 \mathrm{kHz}$ and $\alpha$ was determined by processing $150000 \mathrm{~A} / \mathrm{D}$ converted signals. The downward migration distance $L_{v}$ was defined as the distance from the nozzle exit to the axial position at which $\alpha$ became zero on the centerline of the bath.

\subsubsection{Experimental Apparatus and Procedure}

Figure 3 shows a schematic diagram of the experimental apparatus used for water-air, aqueous glycerol solution-air, and mercury-air systems. For the first two systems transparent acrylic vessels were used. The inner diameters of the vessels were 123,200 , and $390 \mathrm{~mm}$. On the other hand, two brass vessels having inner diameters of 125 and $155 \mathrm{~mm}$ were employed for the mercury-air

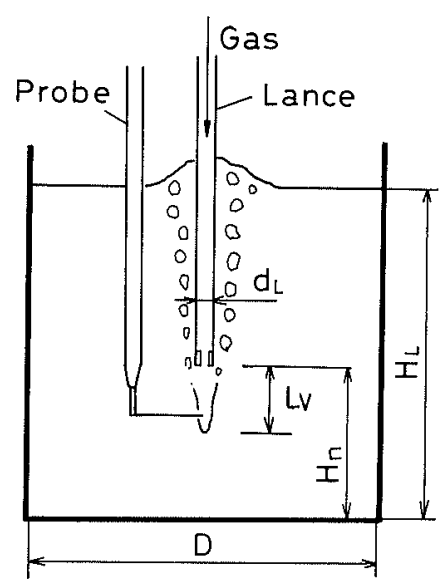

Fig. 2. Definition of the vertical migration distance, $L_{v}$, of bubbles from the lance exit.

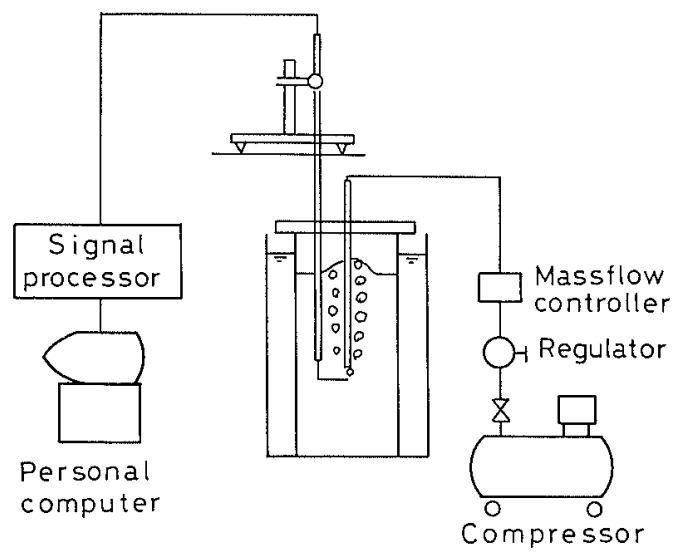

Fig. 3. Experimental apparatus for measuring $L_{v}$ in water-air, aqueous glycerol solution-air and mercury-air systems.

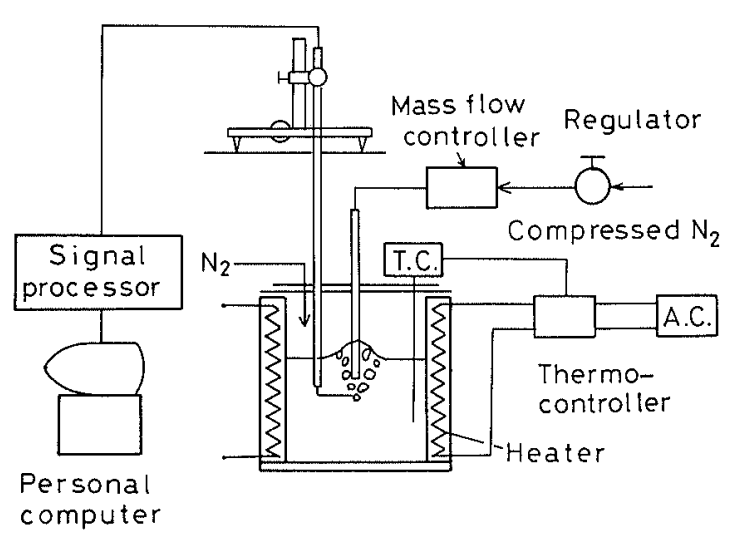

Fig. 4. Experimental apparatus for measuring $L_{v}$ in Wood's metal-nitrogen system.

system. Two kinds of aqueous glycerol solutions of the kinematic viscosity of 9.4 and $4.7 \mathrm{~mm}^{2} / \mathrm{s}$ at $25^{\circ} \mathrm{C}$ were used. These solutions were denoted by aqueous glycerol solutions 1 and 2, respectively.

The outer diameter of the lance made of brass was $8 \mathrm{~mm}$, and the inner diameter of the nozzle was 1 or $2 \mathrm{~mm}$. The gas flow rate was changed from 10 to 300 $\mathrm{cm}^{3} / \mathrm{s}$. The electro-resistivity probe was fixed to traverse equipment and moved downward with equal intervals of $1 \mathrm{~mm}$ to measure the local gas holdup on the 
centerline of the bath.

A schematic of the experimental apparatus for the Wood's metal- $\mathrm{N}_{2}$ system is shown in Fig. 4. The cylindrical vessel made of stainless steel had an inner diameter of $125 \mathrm{~mm}$ and a height of $200 \mathrm{~mm}$. The temperature of the bath was kept at $100 \pm 1^{\circ} \mathrm{C}$ by means of a thermocontroller. The other experimental conditions are the same as those reported for the water-air system.

\subsection{Measurement of Liquid Flow Velocity Using a Laser Doppler Velocimeter}

LDV measurements of the axial and radial velocity components were made for the water-air system to reveal the fluid flow behavior induced by bubbles.

A schematic diagram of the experimental apparatus is shown in Fig. 5. The transparent acrylic vessel had an inner diameter of $200 \mathrm{~mm}$ and a height of $400 \mathrm{~mm}$. The depth of tap water bath was $300 \mathrm{~mm}$. In order to reduce the effect of the index of refraction of the vessel as much as possible, the cylindrical vessel was enclosed by another vessel having a rectangular cross section and the same tap water was filled in the outer vessel.

Air was injected into the bath using a compressor. The outer diameter of the lance was $8 \mathrm{~mm}$ and the inner diameter of the nozzle was $2 \mathrm{~mm}$ [see Fig. 5(a)]. This type of lance was named the submerged top lance. The gas flow rate was 82.6 or $160 \mathrm{~cm}^{3} / \mathrm{s}$. The axial distance from the nozzle exit to the bottom of the vessel was 150 or $200 \mathrm{~mm}$.

Air injection also was made through a nozzle shown in Fig. 5(b). The nozzle was screwed inside a brass pipe having a length of $100 \mathrm{~mm}$, an outer diameter of $10 \mathrm{~mm}$ and an inner diameter of $8 \mathrm{~mm}$. The length and inner diameter of the nozzle were 10 and $2 \mathrm{~mm}$, respectively. This type of nozzle was termed the extruded nozzle.

In addition, a conventional type of nozzle attached to

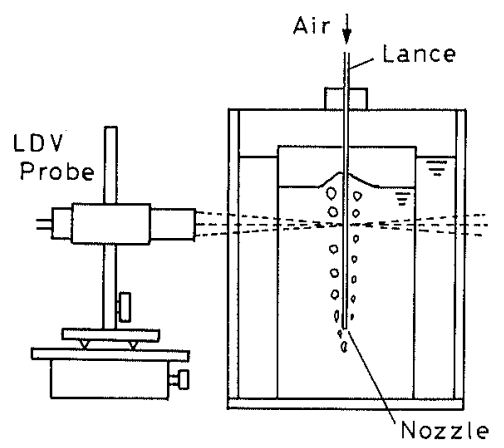

(a) Downward injection

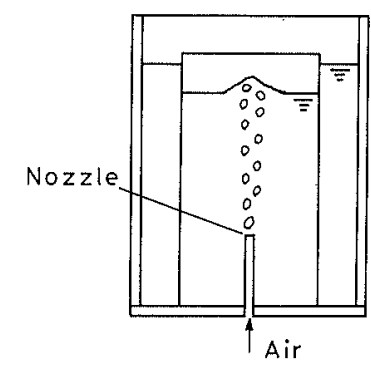

(b) Upward injection

Fig. 5. Experimental apparatus for measuring liquid velocity in water-air system. the center of the bottom wall was named the bottom nozzle.

\subsection{Measurement of Mass Transfer Coefficient}

Figure 6 illustrates a schematic layout of the experimental apparatus for mass transfer measurement. The inner diameter of the vessel was $200 \mathrm{~mm}$ and the height was $400 \mathrm{~mm}$. $\mathrm{FeSO}_{4}$ was added to aqueous $0.1 \mathrm{~N}$ $\mathrm{H}_{2} \mathrm{SO}_{4}$ solution to become $0.1 \mathrm{~mol} / l$. The bath depth was $300 \mathrm{~mm}$. Nitrogen gas was injected into the bath through a nozzle of $d_{n}=2 \mathrm{~mm}$ at three gas flow rates of $82.6,160$, and $240 \mathrm{~cm}^{3} / \mathrm{s}$. The gas flow rate was controlled by using a mass flow controller.

The bath temperature was kept at $25 \pm 0.1^{\circ} \mathrm{C}$ by controlling the water temperature in the jacket by means of a pipe heater, a digital thermocontroller and an air pump. The dimensions of the test electrode made of platinum was $10 \mathrm{~mm} \times 10 \mathrm{~mm} \times 0.4 \mathrm{~mm}$. The surface area of the counter electrode was approximately $4000 \mathrm{~mm}^{2}$. The voltage was kept at $1200 \mathrm{mV}$ so that the limiting current could be measured everywhere in the bath. The electrode was traversed in the radial and axial directions and the limiting current was measured. Surface treatment was repeated at every $15 \mathrm{~min}$ to avoid a decrease in the limiting current due to the contamination of the electrode surface.

The mass transfer coefficient $k_{L}$ was calculated from

$$
I /\left(A n_{r} F\right)=k_{L} C_{b}
$$

where $I$ is the limiting current, $A$ is the surface area of the test electrode, $n_{r}$ is the number of electron responsible for the reaction, $F$ is the Faraday constant, $C_{b}$ is the concentration of $\mathrm{Fe}^{2+}$ ion in the bulk layer. Other details of the measurement method should be referred to the previous paper. ${ }^{6)}$

\section{Experimental Results and Discussion}

\subsection{Swirl Motion of Bubbling Jet}

The critical distance from the bath surface to an axial nozzle position at which the swirl motion ceased was measured for the above-mentioned three kinds of injection systems. The vessel diameter was $200 \mathrm{~mm}$ and the water-air system was used. Figure 7 shows the critical distance $L_{n}$ against the gas flow rate $Q_{g}$. The critical distance for the bottom blowing nozzle which was denoted by $H_{L, l, f}$ was in good agreement with that for the extruded nozzle denoted by $H_{L}-H_{n}$. The bottom wall is located just below the nozzle exit for the bottom

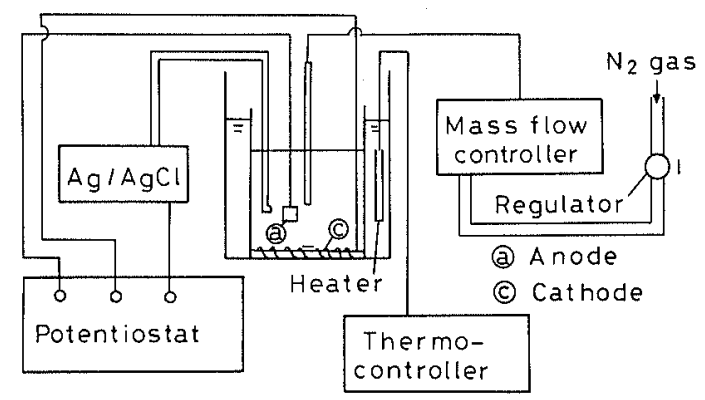

Fig. 6. Experimental apparatus for measuring mass transfer between a platinum flat plate and liquid. 


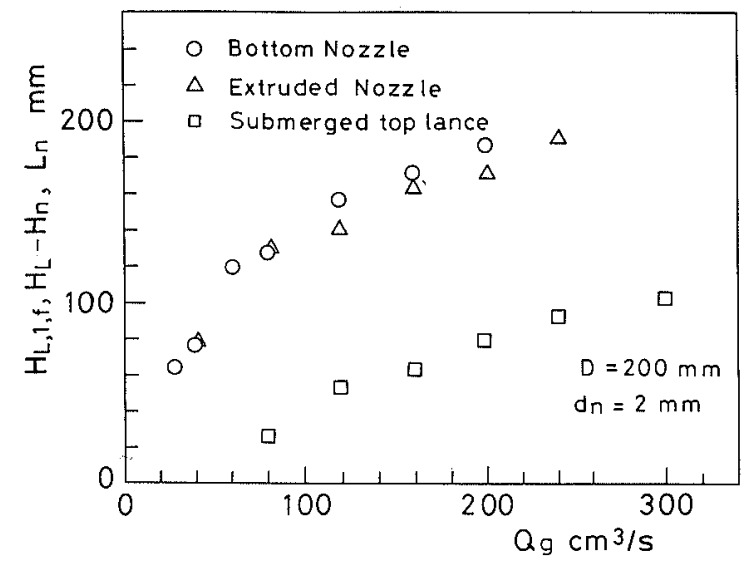

Fig. 7. Critical lance depth or nozzle depth for the cessation of swirl motion in water-air system.

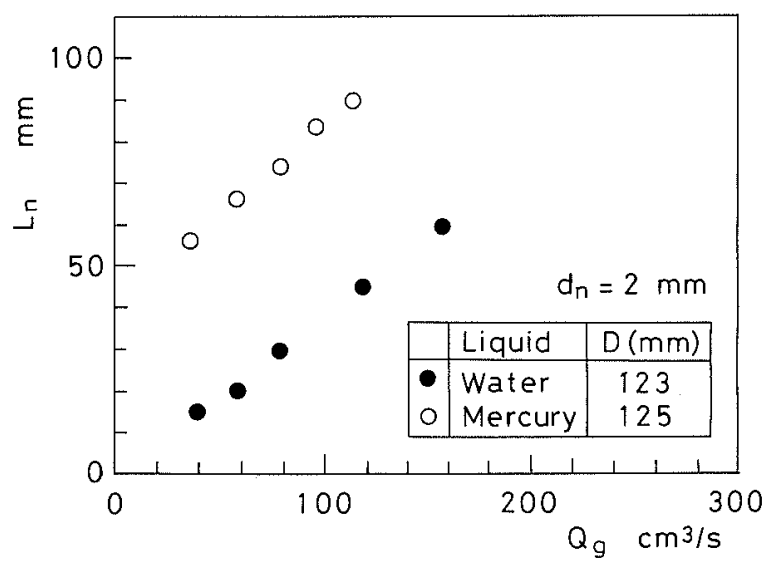

Fig. 8. Critical lance depth for the cessation of swirl motion in water-air and mercury-air systems.

blowing nozzle, while the extruded nozzle is surrounded by water. Consequently, the swirl motion observed here can be classified into the deep water wave because it is independent of the bottom condition. ${ }^{5}$

Figure 8 compares the experimental result of $L_{n}$ for the water bath with that for the mercury bath. The measured values of $L_{n}$ for the mercury bath were found to be much larger than those for the water bath. Measurements were further conducted by changing the inner diameter of the nozzle $d_{n}$ for the mercury bath. The result revealed that $L_{n}$ was independent of $d_{n}$.

The effect of the bath depth $H_{L}$ on $L_{n}$ was investigated for water bath. This effect was not seen as long as the leading edge of the bubbling jet did not come into contact with the bottom wall.

The outer diameter of the lance $d_{L}$ was changed from 8 to $20 \mathrm{~mm}$. The measured values of $L_{n}$ were smaller for $d_{L}=20 \mathrm{~mm}$ than for $d_{L}=8 \mathrm{~mm}$ (see Fig. 9). Therefore an increase in $d_{L}$ suppressed the swirl motion. By referring to a correlation of the critical bath depth for the bottom gas injection, we proposed a method of correlating the critical condition for the cessation of the swirl motion as shown in Fig. 10. In Fig. $10 L_{v}$ is the vertical migration distance of the downward injected bubbling jet and $W e_{d L}$ is a kind of modified Weber number defined by

$$
W e_{d L}=\rho_{L} Q_{g}^{2} /\left[\sigma\left(D-d_{L}\right)^{3}\right]
$$

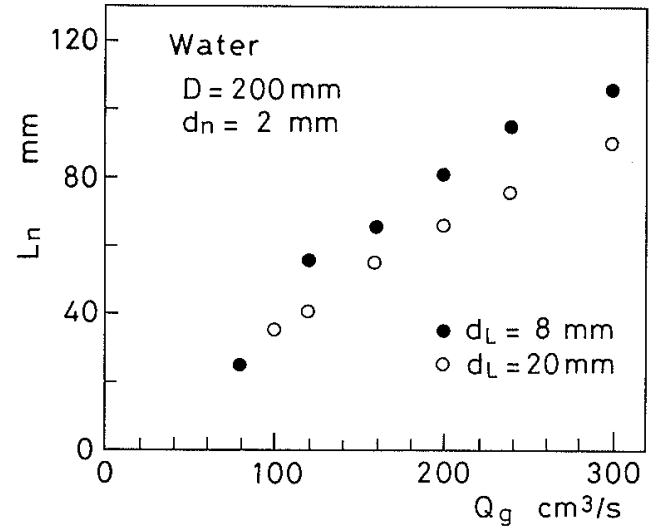

Fig. 9. Effect of lance diameter on the critical lance depth in water-air system.

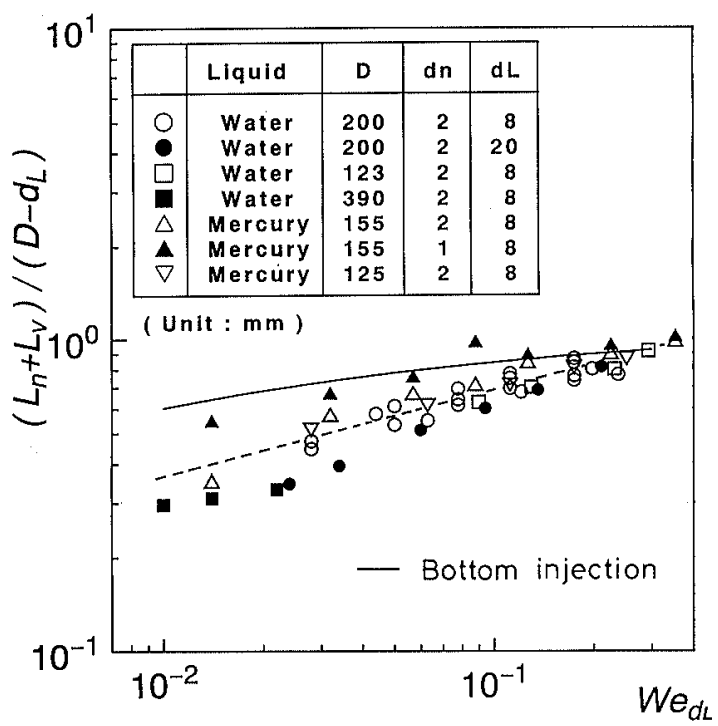

Fig. 10. Correlation of the critical lance depth for the cessation of swirl motion as a function of Weber number.

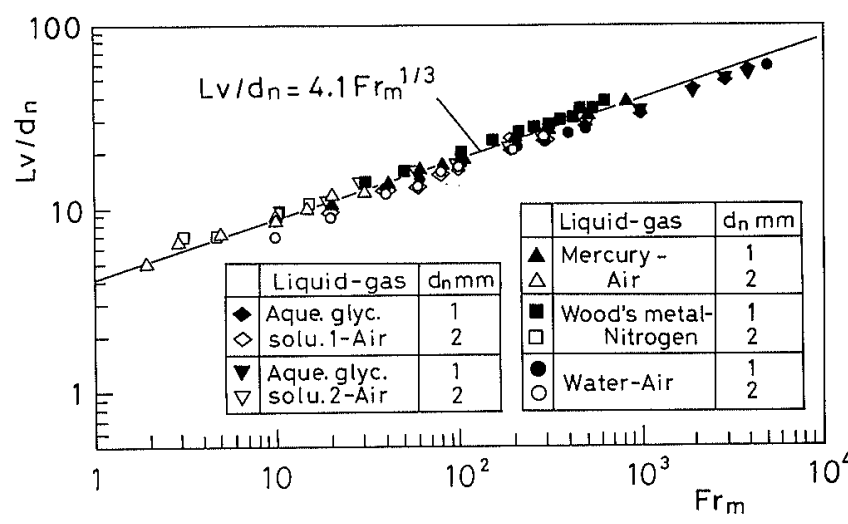

Fig. 11. Relation between vertical migration distance of bubbling jet $L_{v}$ and modified Froude number $\mathrm{Fr}_{m}$.

where $\rho_{L}$ is the density of liquid, $\sigma$ is the surface tension, $\left(D-d_{L}\right)$ is the hydraulic diameter. The functional relationship of $L_{v}$ will be given later.

\subsection{Vertical Migration Distance of Bubbling Jet}

The relation between the vertical migration distance $L_{v}$ and the modified Froude number $F r_{m}$ are shown in Fig. 11. The modified Froude number is a dimensionless 


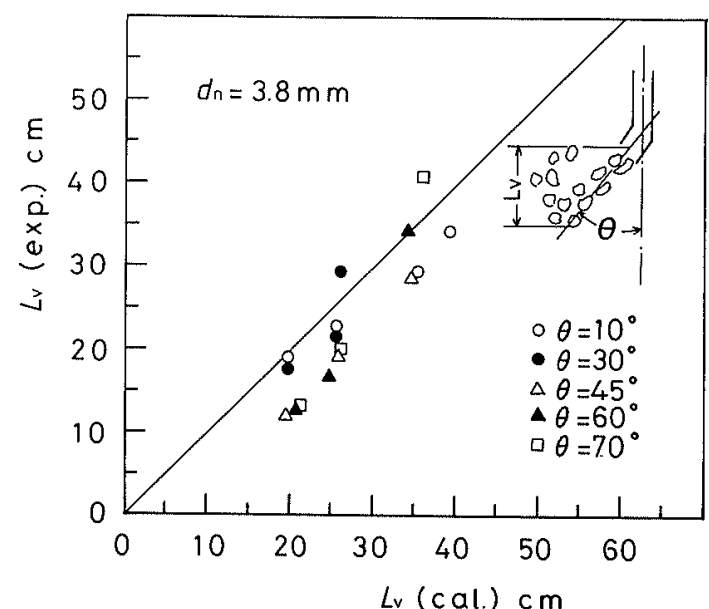

Fig. 12. Comparison of $L_{v}$ between the present estimated value and experimental data by Igwe $e t a l$.

parameter standing approximately for the ratio of the inertia force of injected gas to the buoyancy force of bubbles generated at the nozzle exit.

$$
F r_{m}=\rho_{g} Q_{g}^{2} /\left(\rho_{L} g d_{n}^{5}\right)
$$

where $\rho_{g}$ is the density of gas and $g$ is the acceleration due to gravity.

The solid line in Fig. 11 shows an empirical equation derived here:

$$
L_{v}=4.1 d_{n} F r_{m}^{1 / 3}, \quad 2<F r_{m}<6 \times 10^{3}
$$

Equation (4) can approximate all measured values within a scatter of $\pm 15 \%$.

Ishibashi et al. proposed an empirical equation for the horizontal migration distance $L_{H}$ of a bubbling jet injected horizontally into a water bath through a nozzle installed on the side wall of the vessel. ${ }^{7,8)}$

$$
L_{H}=3.7 d_{n} F r_{m}^{1 / 3}, \quad 1<F r_{m}
$$

Equations (4) and (5) have the same functional relationship, and the difference between their coefficients is at most $10 \%$. Therefore the effect of injection angle on the migration distance of bubbling jet is very small. In other words, the buoyancy force of bubbles does not affect the migration distance significantly. This might be because Eqs. (4) and (5) are derived for the modified Froude number greater than unity.

Igwe et $a l .{ }^{9}$ ) used a water-air system and measured the migration distance of bubbling jet by changing the injection angle of a submerged nozzle. Figure 12 compares their measured values of the vertical migration distance of bubbling jet $L_{v}$ with the present empirical Eq. (4). The measured values of Igwe et al. for $\theta=10^{\circ}$ and $30^{\circ}$ could be satisfactorily approximated by Eq. (4).

Meanwhile, Sano et al. employed water and mercury baths and observed interesting phenomena for a horizontally injected bubbling jet. ${ }^{10,11)}$ Unfortunately, data on horizontal migration distance are not available.

\subsection{Radial Distributions of Bubble and Liquid Flow Characteristics}

Figure 13 shows the radial distributions of gas holdup for a bubbling jet injected through a submerged top lance.

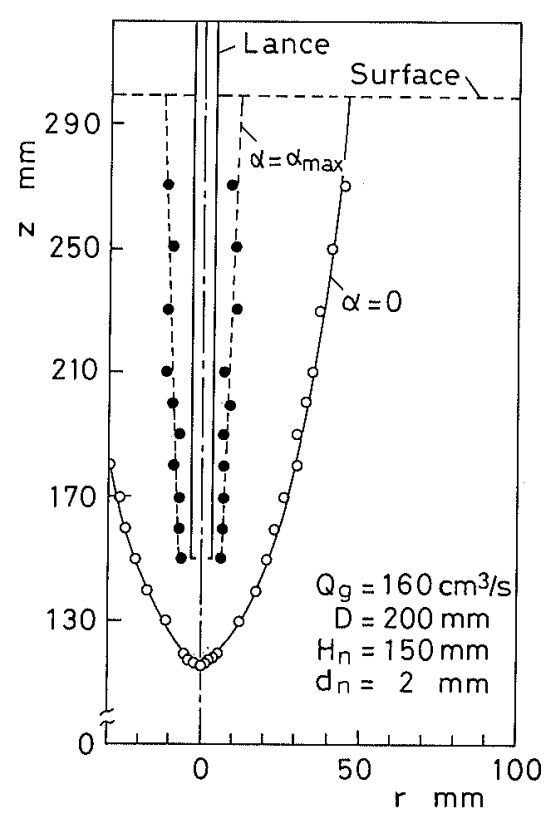

Fig. 13. Gas holdup distributions in the bath.

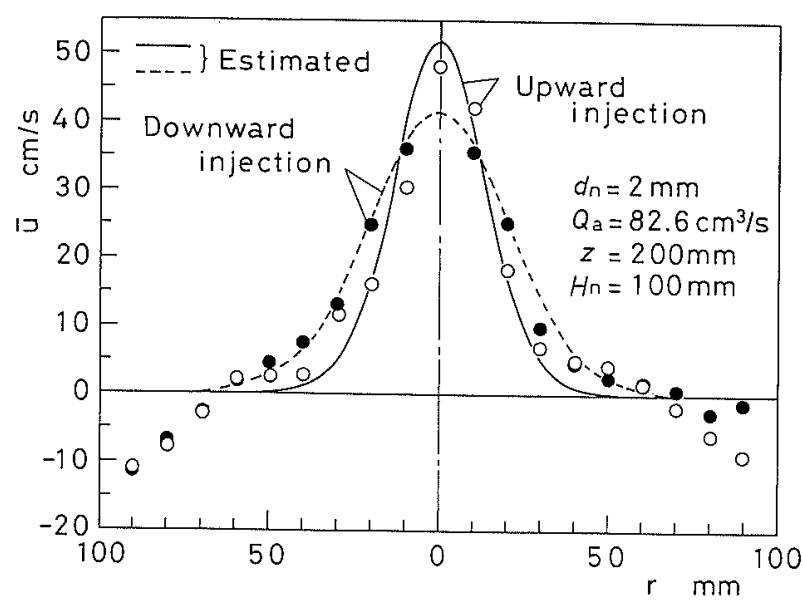

Fig. 14. Distributions of axial mean velocity of water in the bath.

No bubble exists in the region outside the solid line indicated by $\alpha=0$. Since the maximum value of $\alpha$ is located near the lance at every axial position, most bubbles rise along the lance.

Two examples of the radial distribution of the axial mean velocity are shown in Fig. 14. In the region near the vessel axis, the measured values for the upward gas injection are larger than those for the downward gas injection, whereas the radial dispersion of the former bubbling jet is smaller than the latter.

The flow rate of upward moving water was obtained by integrating the radial distribution of the axial mean velocity. The value thus obtained for the downward gas injection was approximately 1.25 times as much as that for the upward gas injection.

In the case of upward gas injection, the radial dispersion of vertical bubbling jet was small in the axial region near the nozzle where the inertia force of injected gas played an important role, and hence the volume of water entrained into the bubbling jet also was small. ${ }^{12)}$ On the other hand, in the case of downward gas injection, bubbles existing below the nozzle exit were displaced in 
the radial direction due to the inertia force of injected gas. Accordingly the radial dispersion of bubbling jet for the downward gas injection became large. This appears to be the cause of the enhancement of upward moving liquid flow rate.

We calculated the radial distribution of the axial mean velocity $\bar{u}$ for the downward gas injection using an empirical equation of $\bar{u}$ originally proposed for the buoyancy region of a bottom blown bubbling jet. ${ }^{13)}$ The liquid flow was assumed to be solely driven by the buoyancy force of bubbles generated at an axial position which is located at $L_{v}$ below the nozzle exit. On the other hand, an empirical correlation for the momentum region of the bottom blown bubbling jet was used for the calculation of $\bar{u}$ for the upward gas injection.

The axial mean velocity $\bar{u}$ can be approximated by

$$
\bar{u}=\bar{u}_{c l} \cdot \exp \left[-\ln 2 \cdot r^{2} / b_{u}^{2}\right]
$$

where $\bar{u}_{c l}$ is the centerline value of $\bar{u}$ and $b_{u}$ is the half-value radius of $\bar{u}$.

Empirical equations of $\bar{u}_{c l}$ and $b_{u}$ for the momentum region of a bottom blown bubbling jet are expressed as follows:

$$
\begin{aligned}
& \bar{u}_{c l}=2.3 u_{r} F r_{m}^{0.036} \\
& u_{r}=\left(g Q_{g} / z\right)^{1 / 3} \\
& b_{u}=b_{\alpha} \\
& b_{\alpha}=b_{\alpha}\left(z_{50}\right) \cdot\left(z / z_{50}\right)^{n} \\
& b_{\alpha}\left(z_{50}\right)=0.42\left(Q_{g}^{2} / g\right)^{1 / 5} \\
& z_{50}=5.0 d_{n} F r_{m}^{1 / 3} \\
& n=0.0338 \log \left(F r_{m}\right)+0.505
\end{aligned}
$$

where $u_{r}$ is a parameter giving a measure of the upward moving mean liquid velocity, $b_{\alpha}$ is the half-value radius of gas holdup, and $z_{50}$ denotes an axial position at which gas flow rate on the centerline of the bubbling jet, $\alpha_{c l}$, is 0.50 .

Meanwhile, we proposed the following empirical equations for the buoyancy region of the bottom blown bubbling jet.

$$
\begin{aligned}
& \bar{u}_{c l}=1.24 u_{r} P^{-0.28} \\
& P=\left(Q_{g}^{2} / g z^{5}\right)^{1 / 5} \\
& b_{u}=b_{\alpha} / 0.65 \\
& b_{\alpha}=0.47 b_{\alpha}\left(z_{5}\right) \cdot \exp \left(0.75 z / z_{5}\right) \\
& b_{\alpha}\left(z_{5}\right)=1.6\left(Q_{g}^{2} / g\right)^{1 / 5} \\
& z_{5}=17\left(Q_{g}^{2} / g\right)^{1 / 5}
\end{aligned}
$$

where $P$ is a kind of Froude number and $z_{5}$ is an axial position at which $\alpha_{c l}=0.05$.

As can be seen in Fig. 14, an agreement between the empirical equation and the measured values is reasonably good for each gas injection type. The same degree of agreement was seen for the downward gas injection at $Q_{g}=160 \mathrm{~cm}^{3} / \mathrm{s}$ though the result is not shown here.

For getting information on the flow pattern in the bath

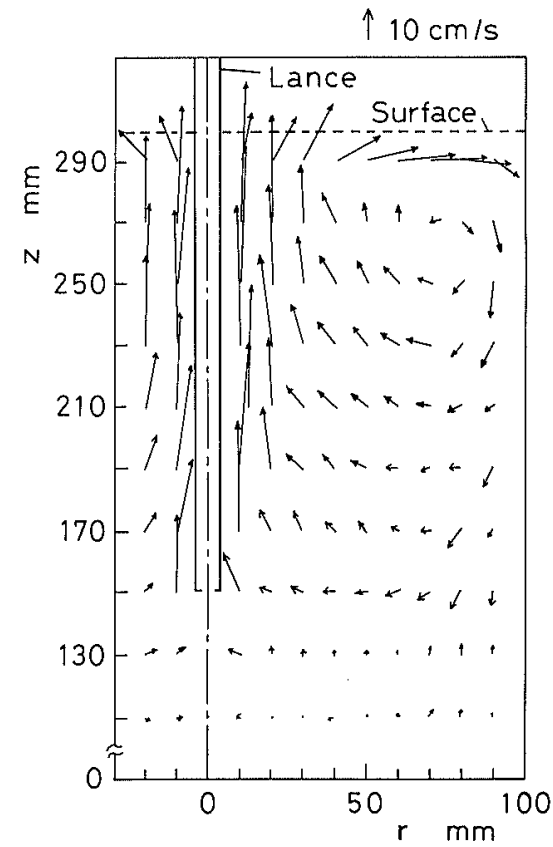

Fig. 15. Mean velocity vectors of water in the bath $\left(Q_{g}=\right.$ $\left.160 \mathrm{~cm}^{3} / \mathrm{s}\right)$.

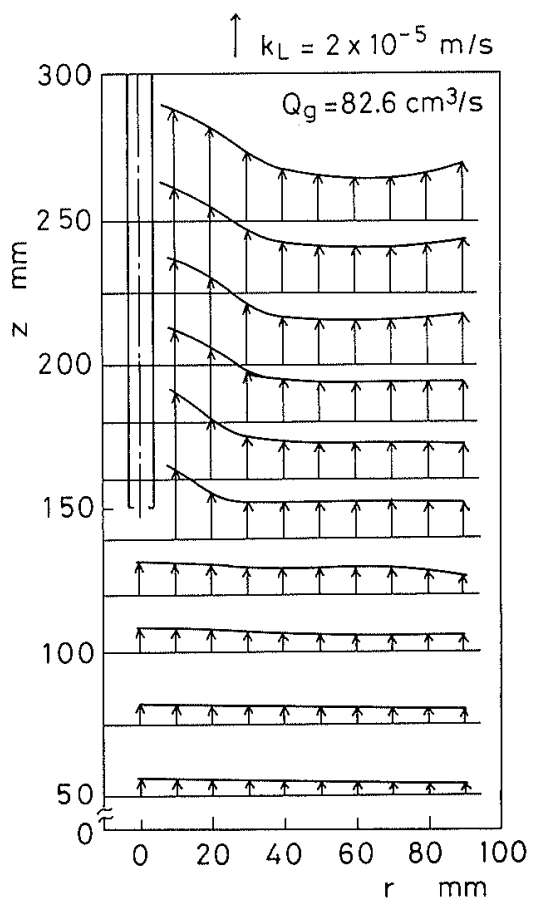

Fig. 16. Distributions of mass transfer coefficient in the bath.

accompanied by downward gas injection through a submerged top lance, the axial and radial mean velocity components were measured using a two-dimensional $\mathrm{LDV}$ for $Q_{g}=160 \mathrm{~cm}^{3} / \mathrm{s}, H_{n}=150 \mathrm{~mm}$, and $H_{L}=300$ $\mathrm{mm}$. Measurements were made at equal intervals of $20 \mathrm{~mm}$ in the axial direction and $10 \mathrm{~mm}$ in the radial direction. The resultant velocity vectors are shown in Fig. 15. In the region above the nozzle exit, a recirculation flow can be seen. The entrainment of water is remarkable in the region just below the nozzle exit because the velocity vectors there directed toward the centerline of the bath. The magnitudes of the velocity vectors are very small further below this region, which means the existence 
of the so-called dead water region near the bottom region of the bath.

\subsection{Mass Transfer Coefficient between a Flat Plate and Liquid}

The mass transfer coefficient between liquid and a flat plate was measured using the well-known electrochemical method. An example of the measurements is shown in Fig. 16. Equation (4) gives the axial migration distance of the bubbling jet $L_{v}$ of approximately $23.8 \mathrm{~mm}$ for the gas flow rate of $82.6 \mathrm{~cm}^{3} / \mathrm{s}$. Accordingly the farthest axial position at which bubbles can arrive is $23.8 \mathrm{~mm}$ below the nozzle exit. In the axial region near the bottom wall where bubbles never reach, the mass transfer coefficient at every measurement position is very small, say less than $1 \times 10^{-5} \mathrm{~m} / \mathrm{s}$.

The distribution of $k_{L}$ in the bath also indicates the existence of the dead water region.

\section{Conclusions}

(1) When gas was injected downward into a cylindrical bath through a submerged top lance, a swirl motion was observed under a certain blowing condition. The critical lance depth $L_{n}$ for the cessation of the swirl motion was given as a function of a modified Weber number.

(2) The downward migration distance of a bubbling jet $L_{v}$ can be given by the following empirical equation for the water-air, aqueous glycerol solution-air, mercury-air, and Wood's metal- $\mathrm{N}_{2}$ systems.

$$
\begin{aligned}
& L_{v}=4.1 d_{n} F r_{m}^{1 / 3} \quad\left(2<F r_{m}<6 \times 10^{3}\right) \\
& F r_{m}=\rho_{g} Q_{g}^{2} /\left(\rho_{L} g d_{n}^{5}\right)
\end{aligned}
$$

where $d_{n}$ is the inner diameter of the nozzle, $F r_{m}$ is the modified Froude number, $\rho_{g}$ is the density of gas, $Q_{g}$ is the gas flow rate, $\rho_{L}$ is the density of liquid, $g$ is the acceleration due to gravity.

(3) The liquid motion in a bath accompanied by downward gas injection was assumed to be driven by the buoyancy force of bubbles generated at the axial position at $L_{v}$ below the nozzle exit. That is, the gas injection position was assumed to be located at $L_{v}$ below the nozzle exit. The axial mean velocity was calculated using an empirical equation originally proposed for a bottom blown vertical bubbling jet. The radial distribution of the measured axial mean velocity was well approximated by the empirical equation.

(4) According to the present experimental results for the mass transfer between a platinum flat plate and liquid in the bath, the so-called dead water region was observed near the bottom of the bath.

\section{REFERENCES}

1) Interfacial Transport Phenomena in Pyrometallurgical Processes, ed. by Committee on Interfacial Transport Phenomena: The Joint Soc. on Iron and Steel Basic Res., (1991-5).

2) Y. Fukunaka, M.-F. Jiang, T. Yamamoto, Z. Asaki and Y. Kondo: Metall. Trans., 20B (1989), 5.

3) The 101-102th Nishiyama Memorial Seminar, Recent Trend in Steelmaking Technologies Using Gas Injection, ed. by ISIJ, Tokyo, (1984).

4) M. P. Schwarz: Chem. Eng. Sci., 45 (1990), 1765.

5) M. Iguchi, S. Hosohara, T. Koga, R. Yamaguchi and Z. Morita: Tetsu-to-Hagané, 78 (1992), 1778; ISIJ Int., 33 (1993), 1037

6) T. Mizushina: Advances in Heat Transfer, Vol. 7, Academic Press, New York, (1971), 89.

7) M. Ishibashi, K. Shiraishi, S. Yamamoto and M. Shimada: Tetsu-to-Hagané, 61 (1975), 111.

8) K. Mori and M. Sano: Tetsu-to-Hagané, 67 (1981), 672.

9) B. U. N. Igwe, S. Ramachandran and J. C. Fulton: Metall. Trans., 4 (1973), 1887.

10) T. Tamura, M. Sano and K. Mori: Tetsu-to-Hagané, 72 (1986), S952.

11) M. Sano, K. Mori, T. Tamura, U. Ryou and S. Sai: CAMP.ISIJ, 2 (1989), 132.

12) M. Iguchi, H. Takeuchi and Z. Morita: Tetsu-to-Hagané, 76 (1990), 5; ISIJ Int., 31 (1991), 246.

13) M. Iguchi, T. Kondoh, Z. Morita, K. Nakajima, H. Hanazaki, T. Uemura and F. Yamamoto: Scaninject VI, Vol. 1, Lurea, Sweden, (1992), 145.

14) M. Iguchi, H. Kawabata, T. Iwasaki, K. Nozawa and Z. Morita: Tetsu-to-Hagané, 76 (1990), 840; ISIJ Int., 31 (1991), 952.

15) M. Iguchi, K. Nozawa, H. Tomida and Z. Morita: Tetsu-toHagané, 77 (1991), 1426; ISIJ Int., 32 (1992), 747.

(Originally published in Tetsu-to-Hagané, 80 (1994), 18, in Japanese) 